\title{
A Soft-Solid Co-Crystalline Electrolyte Combining Advantages of Organics and Ceramics: Thermally, Electrochemically Stable, Highly Conductive (Adiponitrile) ${ }_{2} \mathrm{LiPF}_{6}$
}

Birane Fall ${ }^{a}$, Prabhat Prakash ${ }^{b}$, Jordan Aguirre ${ }^{a}$, Sumanth Chereddy ${ }^{a}$, Parameswara Rao Chinnam $^{a}$, Dmitriy Dikin ${ }^{c}$, Arun Venkatnathan ${ }^{b *}$, Stephanie L. Wunder ${ }^{a *}$, Michael J. Zdilla ${ }^{a *}$ aDepartment of Chemistry, Temple University, 1901 N. 13th St., Philadelphia, PA 19086, USA

${ }^{b}$ Department of Chemistry and Centre for Energy Science, Indian Institute of Science Education and Research, Dr. Homi Bhabha Road, Pashan, Pune : 411008, India.

${ }^{\mathrm{c} M e c h a n i c a l ~ E n g i n e e r i n g ~ D e p a r t m e n t, ~ C o l l e g e ~ o f ~ E n g i n e e r i n g, ~ T e m p l e ~ U n i v e r s i t y, ~} 1947$ North 12th St., Philadelphia, PA 19122 


\section{ABSTRACT}

The solid electrolyte $(\mathrm{ADN})_{2} \mathrm{LiPF}_{6}$ is described. The structure exhibits adiponitrile (ADN)-based channels based on XRD analysis, through which the $-\mathrm{C} \equiv \mathrm{N}$-solvated $\mathrm{Li}^{+}$ions migrate. High conductivity $\left(\sigma \sim 10^{-4} \mathrm{~S} / \mathrm{cm}\right)$ and high lithium ion transference number $\left(t \mathrm{Li}^{+}=0.54\right)$ results from weak interactions between "hard" (charge-dense) $\mathrm{Li}^{+}$ions and "soft" (electronically polarizable) $\mathrm{C} \equiv \mathrm{N}$, compared with the stronger interactions of previously reported "hard" ether oxygen contacts of polyethylene oxide (PEO) or glymes. The surface of the crystal is a liquid nanolayer that binds the grains so that ionically conductive pellets are easily formed without high pressure/temperature treatments. $(\mathrm{ADN})_{2} \mathrm{LiPF}_{6}(\mathrm{~s})$ has a wide electrochemical stability window of 0 to $5 \mathrm{~V}$. $\mathrm{Li}^{0} /(\mathrm{ADN})_{2} \mathrm{LiPF}_{6} / \mathrm{LiFePO}_{4}$ half cells exhibit cycling for $>50$ cycles at $\mathrm{C} / 20, \mathrm{C} / 10, \mathrm{C} / 5$ rates with capacities of $140 \mathrm{mAh}^{-1}$ to $100 \mathrm{mAh}^{-\mathrm{g}^{-1}}$ and efficiencies $>95 \%$. MD simulations and PWDFT calculations offer insights into the molecular basis of the physical and conductivity properties.

\section{INTRODUCTION}

The need for replacement of volatile liquid electrolytes to improve safety in lithium-ion batteries (LIB) and to enable the use of metallic lithium in next-generation solid-state batteries has generated interest in the development of solid electrolytes. These have included polymers, polymer gels (with nonvolatile liquids) and inorganic materials ${ }^{1-3}$. The investigation of lithium or sodium ionconducting ceramics has yielded a wide range of oxide and sulfide-based materials ${ }^{4}$ that are under active investigation as solid electrolytes for LIB or sodium-ion batteries (SIB). While these can 
have good ionic conductivities $(\sigma)$ and lithium-ion transference numbers $\left(\mathrm{t}_{\mathrm{Li}}{ }^{+}\right.$, the fraction of charge carried by $\mathrm{Li}^{+}$), there are still problems associated with lithium dendrite growth during recharge, and poor interfacial contact between the electrolyte and the electrodes. We have been investigating a new class of solid electrolytes: salt-organic cocrystals (also referred to as solvates) of lithium and sodium salts with weakly ligating molecular organic compounds. Similar to lithium ion conducting ceramics (LICC), these new "soft" cocrystals also have channels for ion migration but are not necessarily single-ion conductors. Unlike the rigid anionic lattices of ceramic electrolytes, the channels in the "soft" co-crytsals consist of weakly Lewis basic donor groups of organic molecules, and in some examples, there are no $\mathrm{Li} \cdots$ anion contacts ${ }^{5}$. Previously reported solvates of lithium salts with polyethylene oxide $(\mathrm{PEO})^{6,7}$ or glymes, $\mathrm{CH}_{3} \mathrm{O}-\left(\mathrm{CH}_{2} \mathrm{CH}_{2} \mathrm{O}\right)_{\mathrm{n}=1-5^{-}}$ $\mathrm{CH}_{3},{ }^{8,9}$ can have ionic conductivities higher than the molten materials ${ }^{7}$. Nevertheless, ionic conductivities are very low $\left(\sigma \sim 10^{-7} \mathrm{~S} / \mathrm{cm}\right.$ for PEO solvates ${ }^{7-10}$ and $\sigma \sim 10^{-6} \mathrm{~S} / \mathrm{cm}$ for glyme solvates ${ }^{9}$ ) due to the tight chelation of the "hard" (non-polarizable) lithium ions with the "hard" ether oxygen donors. Previous work in our group has focused on co-crystals of lithium (or sodium) salts with a coordinating ligand that has "soft" (polarizable), weakly electron-donating atoms, e.g. dimethyl formamide (DMF) with $\mathrm{LiCl}^{11}$ or $\mathrm{NaClO}_{4}{ }^{12}$, isoquinoline with $\mathrm{LiCl}^{13}$, or adiponitrile (ADN) with $\mathrm{NaClO}_{4}{ }^{14}$, where the weaker binding promotes higher conductivity. Some of these cocrystals melt at moderate temperatures, ${ }^{12,14}$ and can therefore be melt-cast, in contrast with inorganic electrolytes, where the grains need to be sintered at high pressures and temperatures.

In the current work, soft cocrystals formed between $\mathrm{LiPF}_{6}$ and $\mathrm{ADN}$ are investigated experimentally and theoretically. The components of the current co-crystals, $\mathrm{LiPF}_{6}$ and ADN, have been extensively used in liquid or polymeric electrolyte systems. $\mathrm{LiPF}_{6}$ is the lithium salt used in most commercial LIBs despite its poor thermal stability in liquid solution and in pure form. The 
most studied, more thermally stable replacement salt, LiTFSI, has limited use due to high cost and since it is known to be corrosive to the aluminum current-collectors for the cathodes ${ }^{15}$. Polar nitrile or cyano- $(-\mathrm{C} \equiv \mathrm{N})$ groups, with high dipole moments and dielectric constants of $\sim 30$, have been investigated to solvate lithium ions instead of the ether oxygens of polyethylene oxide (PEO) or glymes. Recent reviews have focused on their incorporation as functional groups in liquids, plasticizers, plastic crystals (particularly succinonitrile $(\mathrm{SN})^{16,17}$ ), gels (e.g., polyacrylonitrile $(\mathrm{PAN})^{18-27}$ ), PAN polymer-in-salt ${ }^{28-31}$ and solid electrolytes used for LIB applications ${ }^{32}$. These materials often have high anodic oxidation potentials $\left(>4.5 \mathrm{~V} v s . \mathrm{Li}^{+} / \mathrm{Li}\right)$ and are thus resistant to electrochemical oxidation ${ }^{33,34}$ and therefore have the potential to be used with high voltage cathodes $^{35-37}$, e.g., $\mathrm{Li}[\mathrm{Mn}, \mathrm{Ni}, \mathrm{Co}] \mathrm{O}_{2}$. $\mathrm{ADN}$ has also been shown to enable the use of high voltage cathodes when added in small amounts $(1 \%)$ to other electrolyte solutions, by film formation ${ }^{38}$ or strong coordination between the $\mathrm{Ni}^{4+}$ on $\mathrm{N}$-rich cathode surfaces and the nitrile groups ${ }^{39}$. However, they suffer from poor reductive stability (so that they spontaneously react with $\mathrm{Li}$ metal, the $\mathrm{Li}^{+}$ ion cannot be reversibly intercalated into graphite, and stable solid electrolyte interfaces (SEIs) do not form $)^{34}$, but can be used with $\mathrm{Li}_{4} \mathrm{Ti}_{5} \mathrm{O}_{12}\left(1.55 \mathrm{~V} \mathrm{vs} \mathrm{Li}^{+} / \mathrm{Li}\right)$ anodes ${ }^{17,40}$, or with graphitic anodes by addition of SEI forming co-solvents ${ }^{33,41}$. More recently, it was shown that low concentrations of $\mathrm{ADN}(1 \%)$ in mixed electrolytes formed stable SEIs on $\mathrm{Li}^{0}$ metal ${ }^{39}$. Interestingly, and of importance for the current work, the reductive stability of acetonitrile (AN) was improved in concentrated (> $4 \mathrm{M}$ ) salt solutions, since all of the acetonitrile molecules were coordinated to $\mathrm{Li}^{+}$ ions $^{42}$. In dilute solution, the LUMO is based on $\mathrm{AN}$ molecules (coordinating with the $\mathrm{Li}^{+}$ions), while in superconcentrated solutions, the LUMO was localized on the TFSI anion, preventing reductive degradation of the nitrile, and suggesting plausibility of anion reduction during charging ${ }^{42}$. 
Here we investigate the structure, thermal and electrochemical properties of the soft solid crystal of adiponitrile and $\mathrm{LiPF}_{6},(\mathrm{ADN})_{2} \mathrm{LiPF}_{6}$, which has an effective molarity of $\sim 4.5 \mathrm{M}$. We demonstrate this material has desirable physical properties, including melt- and press-castability, high conductivity for an organic solid electrolyte $\left(\sim 10^{-4-} \mathrm{S} \cdot \mathrm{cm}^{-1}\right)$, a wide electrochemical stability window of 0 to $5 \mathrm{~V}$ and stable cycling for $>50$ cycles at $\mathrm{C} / 20, \mathrm{C} / 10, \mathrm{C} / 5$ rates with capacities of $140 \mathrm{mAh}_{-\mathrm{g}} \mathrm{g}^{-1}$ to $100 \mathrm{mAh}-\mathrm{g}^{-1}$ and efficiencies $>95 \%$. Further, it improves the stability of the $\mathrm{LiPF}_{6}$ electrolyte over commercial liquid solutions by isolating the $\mathrm{Li}^{+}$and $\mathrm{PF}_{6}$ ions in separate channels.

\section{RESULTS AND DISCUSSION}

\section{Structural and thermal characterization}

The parent compound is prepared by heating commercially available $\mathrm{LiPF}_{6}$ in excess adiponitrile, in which it is sparingly soluble at room temperature ${ }^{41}$. After complete dissolution by $165^{\circ} \mathrm{C}$, cooling of the solution yields crystalline material. The X-ray single-crystal structure shows that the stoichiometry is 2 moles of $\mathrm{ADN}$ to 1 mole of $\mathrm{LiPF}_{6},(\mathrm{ADN})_{2} \mathrm{LiPF}_{6}($ Figure 1a). Other dinitrile solvates, including ADN, also form 2:1 molar ratios of dinitrile:LiTFS ${ }^{43}$. In $(\mathrm{ADN})_{2} \mathrm{LiPF}_{6}$, there are linear parallel ionic channels of $\mathrm{Li}^{+}$(Figure 1b), where the shortest distance between two successive $\mathrm{Li}^{+}$ions is $6.23 \AA$ in the $b$-crystallographic direction. Each $\mathrm{Li}^{+}$ion is coordinated to 4 cyano groups, and does not interact with any $\mathrm{PF}_{6}^{-}$anions. The presence of $\mathrm{Li}^{+}$channels in the complex may allow migration of $\mathrm{Li}^{+}$in a low-affinity matrix. Other dinitrile solvents, including ADN, form stable solvates at 2/1 molar ratios of dinitrile/LiTFSI ${ }^{43}$.

The experimentally obtained powder X-ray diffraction (PXRD) pattern of $(\mathrm{ADN})_{2} \mathrm{LiPF}_{6}$ agrees with the PXRD calculated from the single crystal data (Figure S1a). PXRD data before and after conductivity measurements (Figure S1b), and whether pressed or prepared in a glass fiber mesh 
(Figure S1c) are the same. The XRD data do not show the presence of frozen ADN at low temperature (Figure S1d), nor parent $\mathrm{LiPF}_{6}$. An important consequense of the isolation of the $\mathrm{PF}_{6}{ }^{-}$ anion from the Lewis acidic lithium is the improvement of the thermal stability of the salt; the thermogravimetric analysis (TGA) data (Figure S2) show that the stability of $\mathrm{LiPF}_{6}$ is increased from decomposition temperatures of $100{ }^{\circ} \mathrm{C}$ for pure $\mathrm{LiPF}_{6}$ to $>160{ }^{\circ} \mathrm{C}$ for $(\mathrm{ADN})_{2} \mathrm{LiPF}_{6}$ upon incorporation into the co-crystal, such that the stability of the co-crystal is limited by the boiling point of ADN. This is most likely because the segregation of the ions into separate channels prevents the formation of the decomposition product LiF. Its important to note that $\mathrm{T}_{\mathrm{d}}$ of cocrystals of $(\mathrm{ADN})_{2} \mathrm{LiPF}_{6}$ is lower than the $\mathrm{T}_{\mathrm{m}}$ (Figure 2a) due to the continuous removal of ADN solvent molecules via $\mathrm{N}_{2}$ gas purge during the TGA experiment. However, in a closed system, such as during DSC mearements, the cocrystals show good thermal stability (up to $200{ }^{\circ} \mathrm{C}$ ).
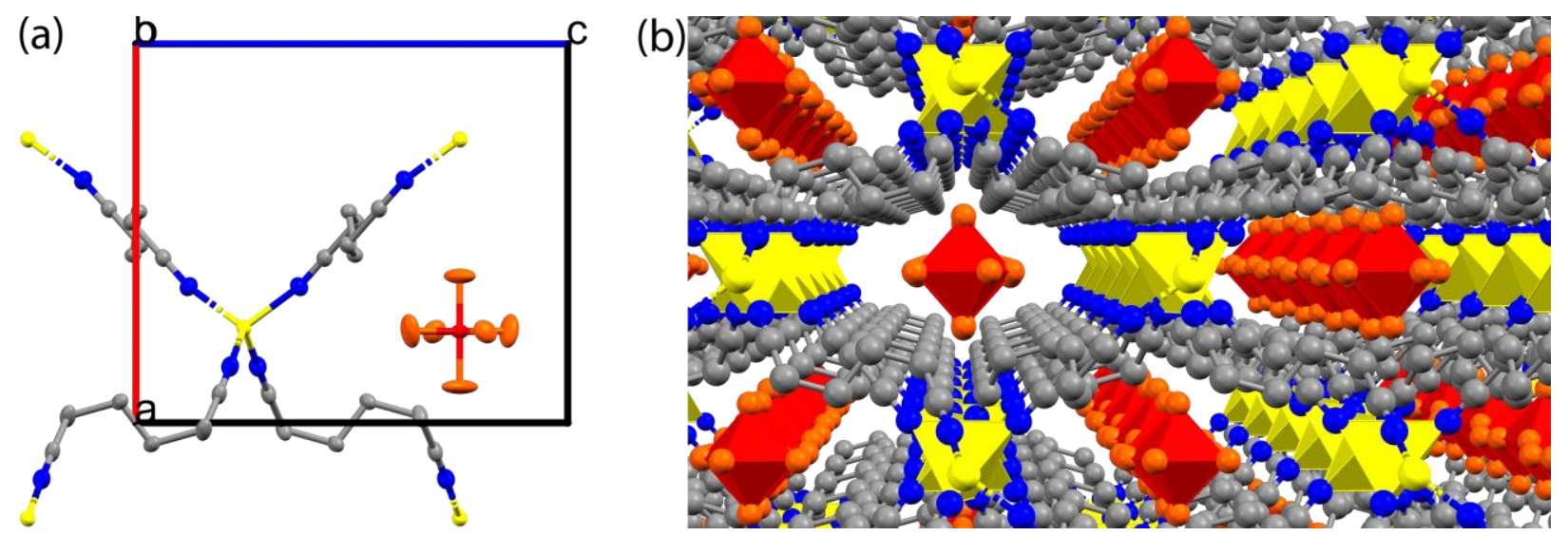

Figure 1. Crystal structure of soft-solid co-crystalline (ADN) ${ }_{2} \mathrm{LiPF}_{6}$ electrolyte: (a) Representation of the basic structural unit of $(\mathrm{ADN})_{2} \mathrm{LiPF}_{6}$ showing tetracoordinated $\mathrm{Li}^{+}$ions with four $\mathrm{ADN}$ molecules, each shared with a second symmetry equivalent Li atom, and where $\mathrm{PF}_{6}{ }^{-}$anions occupy the available interstitial pocket in the crystal structure; (b) Packing diagram of $(\mathrm{ADN})_{2} \mathrm{LiPF}_{6}$ showing the channels of $\mathrm{Li}^{+}$ions in the low affinity matrix in the crystal structure. - Gray- C; Yellow- Li; • Blue- N; • Red- P; and • Orange- F. 
Differential scanning calorimetry (DSC) data (Figure 2a) show that the co-crystals of $(\mathrm{ADN})_{2} \mathrm{LiPF}_{6}$ melt at $182{ }^{\circ} \mathrm{C}$, and reveal the presence of a small amount of $\mathrm{ADN}$ in the cocrystal (Figure S5). Melting of this ADN contaminant occurs at approximately the same temperature as neat ADN, while crystallization occurs at slightly lower temperatures than neat ADN, suggesting confinement effects might play a role. The small amount of free and (i.e., not coordinated to $\mathrm{Li}^{+}$) in the $(\mathrm{ADN})_{2} \mathrm{LiPF}_{6}$ co-crystal is also observed in the Raman spectra (Figure 2b). For pure adiponitrile there is only a single peak at $2241.7 \mathrm{~cm}^{-1}$, while for the co-crystal, there is a large peak at $2273.6 \mathrm{~cm}^{-1}$ and a very small peak at $2242.7 \mathrm{~cm}^{-1}$ slightly red-shifted higher in wavenumber compared with neat ADN (2241.7 $\left.\mathrm{cm}^{-1}\right)$. Both peaks have been observed in other liquid dinitrile/LiX salts (e.g. succinonitrile/LiTFSI) as a function of LiX concentration. ${ }^{43}$, and have been assigned respectively to the coordinated and free "terminal" $\mathrm{C} \equiv \mathrm{N}$ adiponitrile groups ${ }^{44,45}$. The vibrational frequencies and Raman intensities calculated from DFT (Figure 2c, Table S1) in the gas phase support the observation that free $\mathrm{ADN}$ possesses vibrational frequencies approximately $15 \mathrm{~cm}^{-1}$ lower than those in the cocrystal. The slight red shift in the peak maximum of the weak experimental Raman band of $(\mathrm{ADN})_{2} \mathrm{LiPF}_{6}$ compared with free $\mathrm{ADN}$ in the $(\mathrm{ADN})_{2} \mathrm{LiPF}_{6}$ cocrystals suggests that the $\mathrm{ADN}$ are not free but instead are at the edges of the $(\mathrm{ADN})_{2} \mathrm{LiPF}_{6}$ cocrystals, with one of the $\mathrm{C} \equiv \mathrm{N}$ bonded to $\mathrm{Li}^{+}$and the other not bonded and "dangling" at the interface, as supported by DFT calculations .

MD simulations of the structure may be used to visualize and understand the molecular processes underlying experimentally observed thermal stability properties. Simulations were performed using a bulk phase periodic supercell, Model $P$, which consisted of a supercell (125 unit cells, i.e. 20000 atoms) representing the bulk phase of the $(\mathrm{ADN})_{2} \mathrm{LiPF}_{6}$ co-crystals. Model $P$ was simulated under isothermal isobaric $(N p T)$ ensemble conditions for a 20 ns equilibration at 
different constant temperatures ranging from $100 \mathrm{~K}$ to $550 \mathrm{~K}$ (Figure S3). The equilibrated configurations at $100 \mathrm{~K}, 200 \mathrm{~K}$ and $298 \mathrm{~K}$ predict a structured network of tetrahedral $\mathrm{Li}^{+}$ions coordinated by ADN. A visual inspection of snapshots shows that this networks become irregular at $400 \mathrm{~K}\left(=127^{\circ} \mathrm{C}\right)$ and the crystalline structure completely melts at $500 \mathrm{~K}\left(=227^{\circ} \mathrm{C}\right.$, Figure S3), which is in agreement with the melting regime observed in DSC data (430 K - 460 K, Figure S2).

To quantify the nature of all relevant interatomic interactions and crystal deformations, radial distribution functions (RDFs) and coordination numbers for different atom-pair interactions were calculated. For these calculations, the equilibrated model $P$ was simulated for production under a canonical isothermal (NVT) ensemble conditions for $15 \mathrm{~ns}$. The $\mathrm{RDF}$ calculated for $\mathrm{Li}^{+}---$ $\mathrm{N}\left(\mathrm{ADN}\right.$ ) shows a first solvation shell of $4 \mathrm{~N}$ atoms around $\mathrm{Li}^{+}$ions (at $~ 2 \AA$ ) from $100 \mathrm{~K}$ to 400 $\mathrm{K}$ (Figure S4). This agrees with the observed coordination of $\mathrm{Li}^{+}$ions from the XRD structure. In the case of $\mathrm{Li}^{+}---\mathrm{P}\left(\mathrm{PF}_{6}^{-}\right) \mathrm{RDF}$, the first peak appears at $5.8 \AA$ (larger than the $\mathrm{Li}^{+}---\mathrm{N}$ distance) at low temperatures ( $100 \mathrm{~K}$ to $298 \mathrm{~K}$ ), which suggests that the primary solvation shell of $\mathrm{Li}^{+}$ions is composed of ADN molecules only. At $400 \mathrm{~K}$ and $500 \mathrm{~K}, \mathrm{PF}_{6}{ }^{-}$anions approach the $\mathrm{Li}^{+}(\sim 3.6 \AA$ between $\mathrm{Li}$ and $\mathrm{F}$ ), which indicates breakdown of the $\mathrm{Li}^{+}$--- $\mathrm{ADN}$ networks and replacement of ADN molecules by $\mathrm{PF}_{6}{ }^{-}$anions in the solvation sphere of $\mathrm{Li}^{+}$(i.e. formation of molten $\mathrm{LiPF}_{6}$, where the Li---P distance shrinks to $3.6 \AA^{46}$ ). The structural analysis from RDFs suggests that the co-crystalline structure changes from completely ordered to solvated/separated ion-clusters in $\mathrm{ADN}$ in the temperature range $450 \mathrm{~K}-500 \mathrm{~K}$, similar to the experimental melt temperature of $(\mathrm{ADN})_{2} \mathrm{LiPF}_{6}$. 
(a)

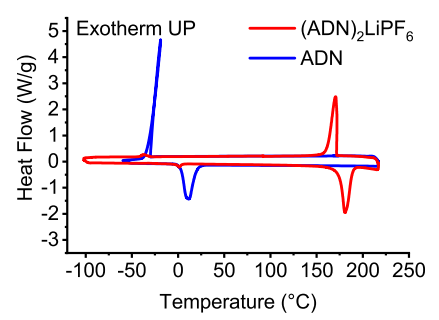

(d)

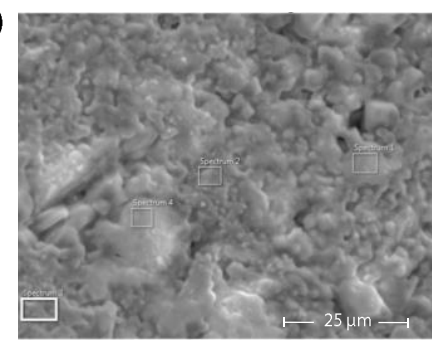

(b)

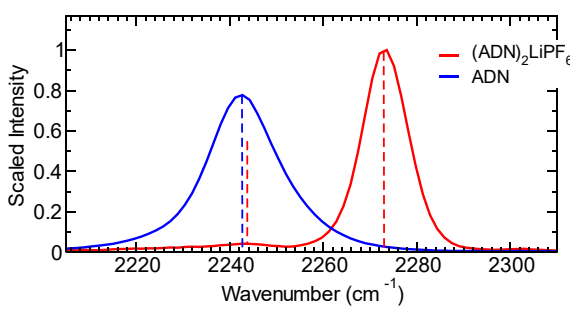

(e)

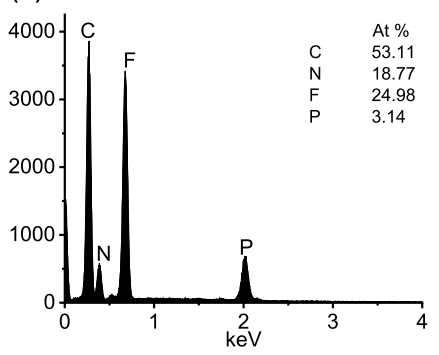

(c)

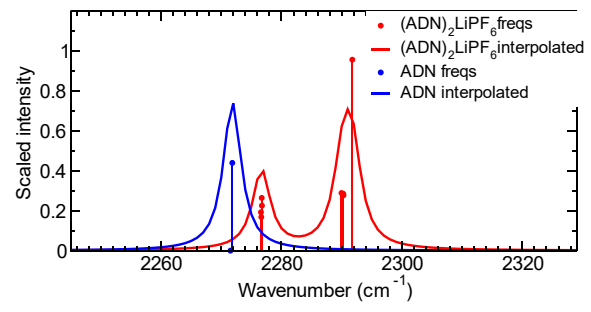

(f)

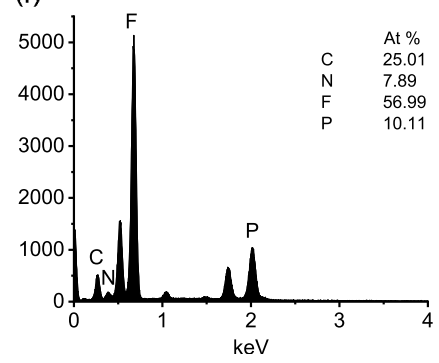

Figure 2. Thermal, structural, and spectroscopic evidence of free solvent molecules at the grain-boundaries of the crystals: (a) DSC data of $(\mathrm{ADN})_{2} \mathrm{LiPF}_{6}$ showing melt and crystallization peaks; (b) Raman spectra in the $-\mathrm{C} \equiv \mathrm{N}$ region from experiment and (c) from DFT calculations, where interpolated curves are obtained by using $1.8 \mathrm{~cm}^{-1}$ of peak half-width at half height; (d) SEM image of pure polycrystalline $(\mathrm{ADN})_{2} \mathrm{LiPF}_{6}$ powder (pressed neat sample), and (e), (f) are EDX of bulk grain and grain boundary regions.

SEM images were obtained for four samples: 1) a pressed pellet of the polycrystalline $(\mathrm{ADN})_{2} \mathrm{LiPF}_{6}$ at RT (Figure 2d, Figure S5), 2) a sample where the heated solution of ADN (excess) and $\mathrm{LiPF}_{6}$ was quenched in liquid $\mathrm{N}_{2}$ and then pressed (Figure S6), 3) the polycrystalline $(\mathrm{ADN})_{2} \mathrm{LiPF}_{6}$ powder incorporated into a glass fiber $(\mathrm{GF})$ filter by synthesis (illustrated in Figure S7), 4) post-mortem sample of a $\mathrm{Li}^{0} /(\mathrm{ADN})_{2} \mathrm{LiPF}_{6} / \mathrm{Li}^{0}$ cell after $\mathrm{Li}$ plating/stripping failure (Figure S13). The $(\mathrm{ADN})_{2} \mathrm{LiPF}_{6}$ crystals - rinsed with diethyl ether - were large, reaching over $100 \mu \mathrm{m}$ in length and $\sim 5 \mu \mathrm{m}$ in width, with rounded edges (Figure S6, a-c). These large $100 \mu \mathrm{m}$ crystals comprise a mosaic structure of smaller, $<1 \mu \mathrm{m}$ crystalline domains (Figure S6i). After pressure was applied, the individual grains fractured into smaller pieces and fused to one another. 


\section{Grain boundaries:}

EDX images (Figure 2e, 2f) of the grains and grain boundary regions show that the relative $\mathrm{C}$ and $\mathrm{N}$ X-ray fluorescence peaks of the $\mathrm{ADN}$ are weaker compared with the $\mathrm{F}$ and $\mathrm{P}$ peaks of the $\mathrm{LiPF}_{6}$ in the grain boundary region than in the grains. This suggests that the grain boundary region is fluid, and that under the vacuum of the SEM, the ADN is evaporated, leaving behind concentrated $\mathrm{LiPF}_{6}$ salt. A nanocrystal of this electrolyte was simulated in the presence of vacuum (model $V$ ) to model TGA behavior (Figure S8). This simulation predicts that ADN molecules evaporate as the cocrystals degrade at high temperature ( $\mathrm{T}>400 \mathrm{~K}$ ) (Figure S8d). In addition, model $V$ also shows that the cocrystals at room temperature possess a liquid-like surface layer (Figure $\mathbf{S 8 b}$ ) similar to other soft solid cocrystals ${ }^{14}$, and which is also seen from SEM analysis of this electrolyte (Figure S5 and S6). This nanoliquid surface behavior is a general characteristic of this class of electrolytes $^{11,12,14,47}$. 
(a)

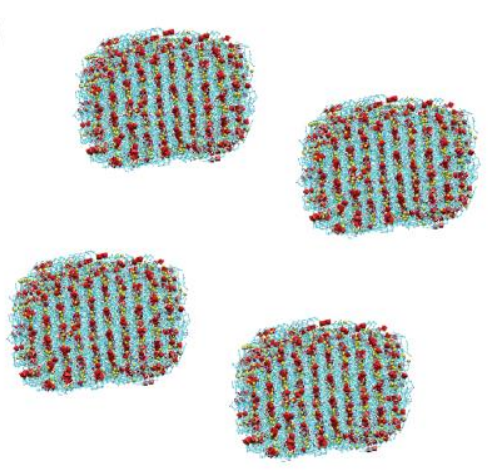

(c)

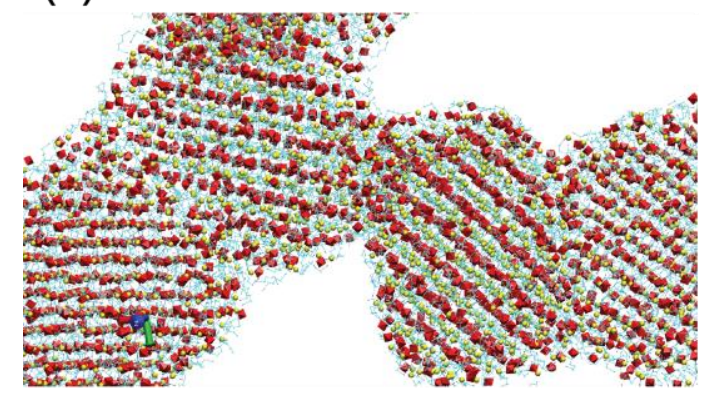

(b)

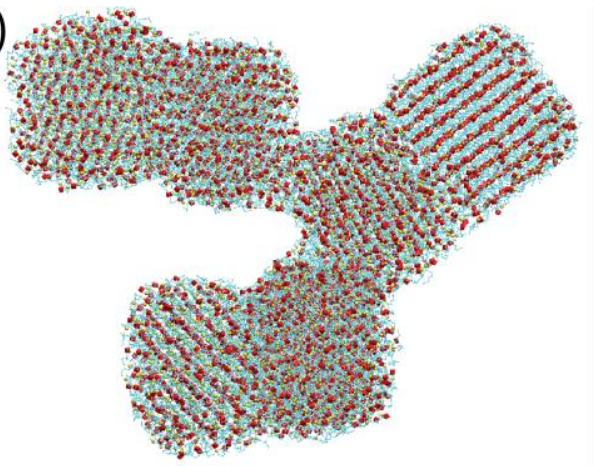

(d)

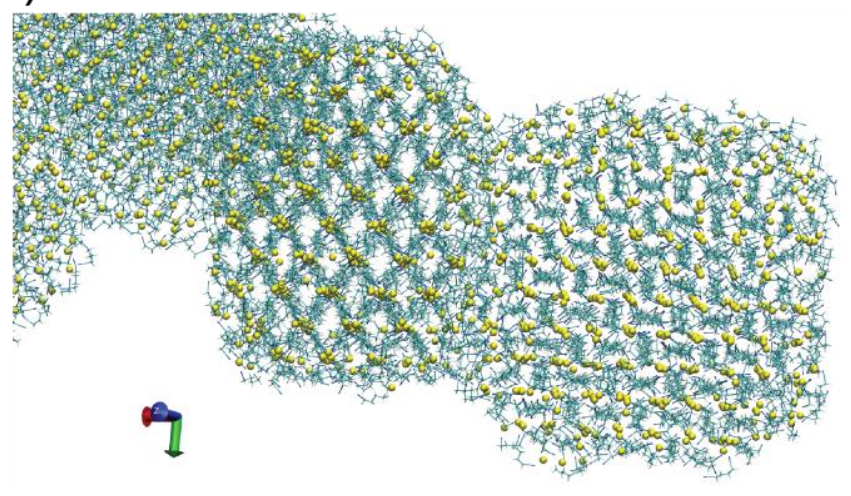

Figure 3. Simulation of model $V_{8 g}$ containing eight grains of $(\mathrm{ADN})_{2} \mathrm{LiPF}_{6}$ (total 160000 atoms): (a) Initial condition of model $V_{8 g}$, only the four grains in the front are visible, the other four grains are behind, (b) model $V_{8 g}$, after a simulation time of $10 \mathrm{~ns}$, under NVT ensemble, (c) a zoomed in view to the multiple grain boundaries, (d) a further zoom in to a grain boundary, where ion channels in bulk are unperturbed, while surface and interfacial region shows disordered ions. A 15 ns trajectory of grain boundary formation can also be seen in the Supplementary movie 1.

To determine the structure of the intergranular interface, model $V_{8 g}$ (surface model) with eight nano-sized grains ( 1 grain $=5 \times 5 \times 5$ unit cells $)$ were simulated in a vacuum box of $30 \times 30 \times 30$ $\mathrm{nm}^{3}$ (Figure 3a). The simulation conditions of model $V_{8 \mathrm{~g}}$ were very similar to model $V$ (e.g., $N V T$ ensemble, presence of large evacuated space). At $t=0$, it was ensured that every grain was completely isolated from the others (initial contact distance between the grains $>$ cut-off distances for potential energy). The simulations show that within a span of few nanoseconds, the grains interact at the surface and form an interfacial layer (Figure 3b, Supplementary movie 1). This interfacial layer does not depend on the orientation of the grains or the size of the box, which 
implies that the formation of an intergranular interface does not require lattice matching. Figure 3c and 3d show a zoomed in view of the grain boundary of a few grains, where the ions present in the bulk remain unaffected in their relative orientation (crystalline) while ions at the interface can be seen to be perturbed. The presence of disordered ions at the fluid interface is can facilitate grain boundary conduction since ion jumps across the grain interface are not required in these regions due to high mobility, in contrast to ceramic organics, whose grains must be sintered to prevent insulating intergrain gaps.

\section{Electrochemical testing:}

The electrochemical impedance spectroscopy (EIS) data (Figure 4a) for a pressed pellet of $\mathrm{ADN}_{2} \mathrm{LiPF}_{6}$ in the temperature range between $-10^{\circ} \mathrm{C}$ and $80{ }^{\circ} \mathrm{C}$ (below its degradation temperature), show a RT conductivity of $\sigma \rightarrow 10^{-4} \mathrm{~S} \mathrm{~cm}^{-1}$, with an Arrhenius activation energy of $\mathrm{E}_{\mathrm{a}}=37.2 \mathrm{~kJ} \mathrm{~mol}^{-1}$. The complex impedance plots are semicircles with an associated capacitance of $1.8 \mathrm{pF} \mathrm{cm}^{-1}$ and a low frequency spike (Warburg diffusion) resulting from ion aggregation at stainless steel blocking electrodes at low frequency. The variation of the DC current as a function of time (Figure S9), in a $\mathrm{Li}(\mathrm{s}) / \mathrm{Li}(\mathrm{s})$ cell, including the correction for the interfacial resistance before polarization $\left(\mathrm{R}_{0}\right)$ and steady-state $\left.\left(\mathrm{R}_{\mathrm{s}}\right), t_{+}=\frac{I_{S}\left(\Delta V-I_{0} R_{0}\right)}{I_{0}\left(\Delta V-I_{0} R_{S}\right)}\right)$, gave a lithium ion transference number of $\mathrm{t}_{\mathrm{Li}}{ }^{+}=0.54$. Thus, unlike inorganic ceramics with a stationary anion lattice and mobile $\mathrm{Li}^{+}$sublattice so that $\mathrm{t}_{\mathrm{Li}}^{+} \rightarrow 1$, here both the anions and cations are mobile. 


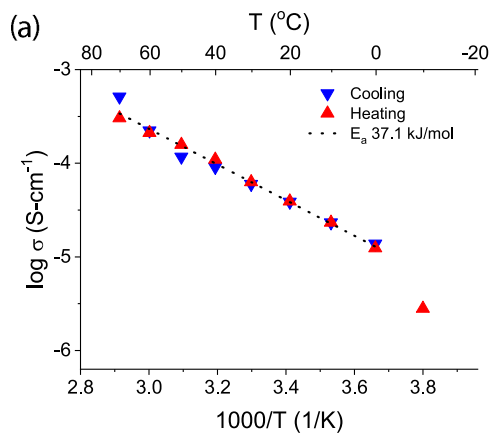

(d)

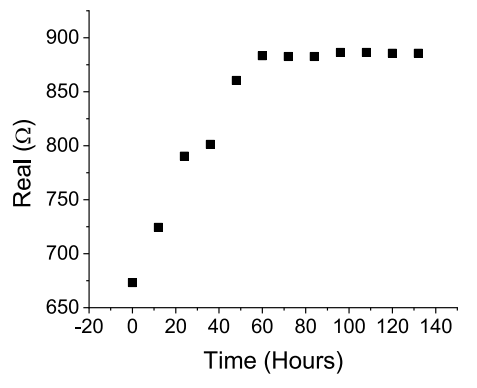

(b)
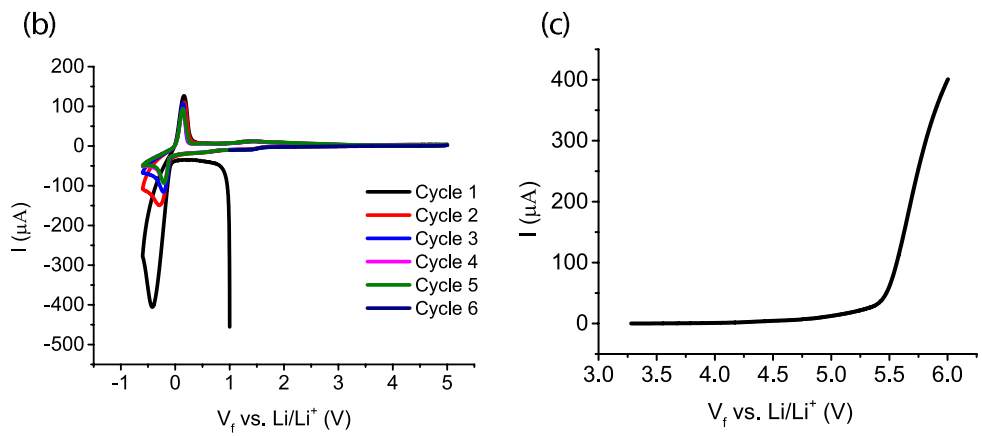

(e)

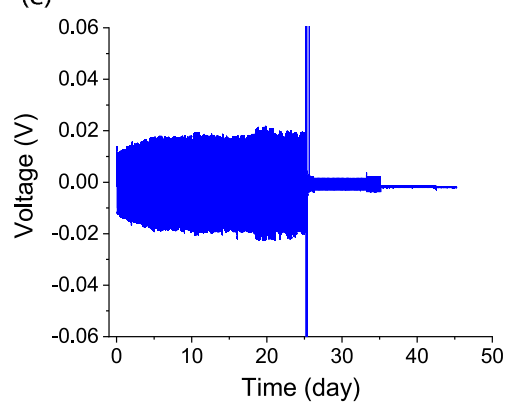

(f)

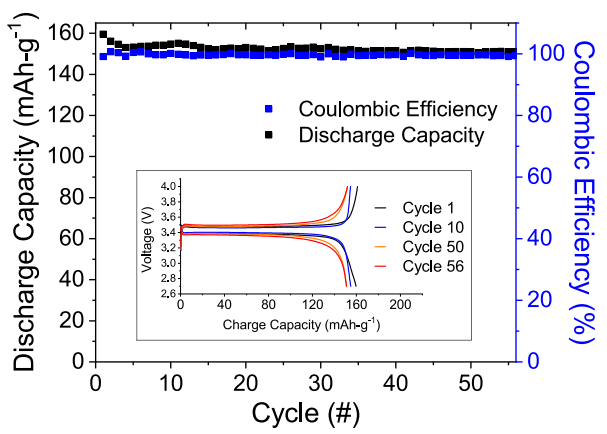

Figure 4. Electrochemical data on (ADN) $)_{2} \mathbf{L i P F}_{6}$ : (a) Variable temperature conductivity data of a pressed neat pellet of $\mathrm{SS} /(\mathrm{ADN})_{2} \mathrm{LiPF}_{6} / \mathrm{SS}$; (b) $\mathrm{CV}$ of $\mathrm{Li}^{0} /(\mathrm{ADN})_{2} \mathrm{LiPF}_{6} / \mathrm{SS}\left((\mathrm{ADN})_{2} \mathrm{LiPF}_{6}\right.$ synthesized in glass fiber); (c) $\mathrm{LSV}$ of $\mathrm{Li}^{0} /(\mathrm{ADN})_{2} \mathrm{LiPF}_{6} / \mathrm{SS}\left((\mathrm{ADN})_{2} \mathrm{LiPF}_{6}\right.$ synthesized in glass fiber); (d) Interfacial resistance as a function of time in $\mathrm{Li}^{0} /(\mathrm{ADN})_{2} \mathrm{LiPF}_{6} / \mathrm{Li}^{0}$ cells using $(\mathrm{ADN})_{2} \mathrm{LiPF}_{6}$ in glass fiber separator at room temperature; (e) Li plating, $2 \mathrm{~h}$ charge/discharge cycles at $\mathrm{J}=0.01 \mathrm{~mA} / \mathrm{cm}^{2}$ for 120 cycles, $\mathrm{J}=0.05 \mathrm{~mA} / \mathrm{cm}^{2}$ for 60 cycles and $\mathrm{J}=0.1 \mathrm{~mA} / \mathrm{cm}^{2}$ for 60 cycles; same cell as in (d); and (f) Discharge capacity and Coulombic efficiency as a function of cycle number in $\mathrm{Li}^{0} /(\mathrm{ADN})_{2} \mathrm{LiPF}_{6} / \mathrm{LiFePO}_{4}$ cell at $\mathrm{C} / 10$ rate at $25{ }^{0} \mathrm{C}$; Inset shows the voltage vs. charge capacity for cycle \# 1, 10, 50 and 56.

ADN has excellent oxidative stability ${ }^{41,48}$, and the oxidation current begins to increase only at 5V

(Figure 4b and Figure 4c). Unfortunately, Li metal is thermodynamically unstable with almost any organic solvent, leading to side reactions that consume both Li metal and the electrolyte ${ }^{49}$. However, a piece of $\mathrm{Li}^{0}$ metal placed in $\mathrm{ADN}$ (with or without $\mathrm{LiPF}_{6}$, which does not dissolve at RT) is much more resistant towards reaction than when placed in acetonitrile (AN). It remains shiny for several days, and the solution does not turn a light yellow for weeks to months (Figure S10). By contrast, when Li metal was placed in dilute LiTFSI/AN, the Li metal quickly dissolved, 
and the solution turned yellowish ${ }^{42}$. This difference is possibly due to the long, nonpolar hydrocarbon chains in ADN.

ADN is known to be thermodynamically unstable at low potentials $\left(\sim 0.6 \mathrm{~V}\right.$ vs $\left.\mathrm{Li} / \mathrm{Li}^{+}\right){ }^{50}$, as is acetonitrile (AN). However, nitrile solvents are stabilized with respect to reaction with lithium metal in the presence of concentrated salts. ${ }^{41}$ Reversible $\mathrm{Li}^{0}$ stripping/plating is observed for $\mathrm{ADN}_{2} \mathrm{LiPF}_{6}$ (Figure 4b), which has an effective molarity of 4.5M. In contrast, while in dilute AN/LiTFSI ( $<3 \mathrm{M})$ Li stripping is not observed ${ }^{42}$. During repeated lithium stripping, the oxidation peak at $\sim 0.5 \mathrm{~V}\left(\mathrm{vs} \mathrm{Li}^{+} / \mathrm{Li}\right)$ superimposes onto itself, while during lithium plating, the reduction peak at $\sim-0.5 \mathrm{~V}$ decreases from the $1^{\text {st }}$ through the $3^{\text {rd }}$ cycles and then remains stable. This suggests that a stable SEI layer is formed during the first three cycles. The reactions at the Li surface during Li cycling are determined by the thermodynamic electrochemical stability window of the electrolyte, which is dominated by the frontier orbitals (HOMO and LUMO) of the salt and solvent ${ }^{51}$. During the cathodic scan (lithium plating), electrolyte components are reduced and deposited on the Li metal to form the solid electrolyte interface (SEI) layer. In the electron rich environment of the anode, the SEI will be formed by the component that is most easily reduced (i.e. the component with the lowest-energy LUMO). Qualitatively, interaction/association of a solvent or anion with $\mathrm{Li}^{+}$lowers the energy of the LUMO making the ligating species more easily reduced. In concentrated $\mathrm{LiX}$ solutions, formation of contact ion pairs result in preferential reduction of the anion ${ }^{52}$. In $(\mathrm{ADN})_{2} \mathrm{LiPF}_{6}$ the $\mathrm{Li}^{+}$ion is solvated by the ADN (as shown from its crystal structure), which suggests ADN to be more easily reduced, and thus forms the SEI. This is predicted quantitatively for $(\mathrm{ADN})_{2} \mathrm{LiPF}_{6}$ in Figures S11, where projected density of states (DOS), obtained from plane-wave DFT calculations, show that after addition of an electron, the bandgap decreases and the LUMO is located on the ADN, particularly the carbon atom. Further 
confirmation that the reduction reaction occurs predominantly on ADN, comes from differential electron density maps (Figure S12), which show that addition of an excessive electron changes the electron density close to $\mathrm{CN}(\mathrm{ADN})$ compared with the $\mathrm{PF}_{6}{ }^{-}$anion. Further, the absence of free solvent has also been suggested to mitigate the reductive decomposition by affecting an upward shift in the equilibrium potential of the Li electrode (from the Nernst equation) and to increase the stability of the SEI, by the lack of solvent to dissolve the $\mathrm{SEI}^{52}$. As discussed later in the mechanism of $\mathrm{Li}^{+}$ion conduction, in the $(\mathrm{ADN})_{2} \mathrm{LiPF}_{6}$ cocrystals the cyano groups do not undergo long range migration during the conduction process, and thus there is not continual replenishment of cyano groups to the $\mathrm{Li}^{0}$ metal surface, and as a result, there is a cessation of SEI formation after a few cycles.

\section{Post-mortem analysis:}

The ideal properties of an SEI are that it is thin, flat, electrically insulating (to suppress further reductive decomposition), and ionically conductive. Interfacial resistance (Figure 4d) in the $\mathrm{Li}^{0} /(\mathrm{ADN})_{2} \mathrm{LiPF}_{6} / \mathrm{Li}^{0}$ cell stabilized at about $900 \Omega$ after 3 days. Lithium plating in the same cell (Figure 4e) was stable for 20-25 days at low current densities $\left(\mathrm{J}=0.01 \mathrm{~mA} / \mathrm{cm}^{2}\right)$ but failed at higher current densities. Post-mortem analysis showed that the Li surface was black. SEM images (Figure S13) indicate that the SEI was rough (not flat) with a thickness $<5 \mu \mathrm{m}$ after $\sim 30$ days, suggesting a compact but mossy SEI layer, with no obvious dendritic growth. SEM images (Figure S14) and EDX analysis (Figure S15) of the surface showed residual (ADN) ${ }_{2} \mathrm{LiPF}_{6}$ crystals that adhered to the SEI layer, based upon their morphology and dominant C, N, F and P signals, with little or no O. At the SEI layer itself, the major peaks were $\mathrm{O}$ (from $\mathrm{Li}_{2} \mathrm{O}$ ) and $\mathrm{C}$ (from $\mathrm{ADN}$ ), with very little $\mathrm{P}$ and $\mathrm{F}$ (from $\mathrm{PF}_{6}{ }^{-}$). While further investigation is required, these peaks suggest the formation of lithium oxides and carbonates. The formation of compounds containing $\mathrm{C}$ (such as 
carbonates), and the scarcity of $\mathrm{F}, \mathrm{P}$, agree with predications from electronic structure calculations that the $\mathrm{ADN}$ reduction could cause solvent degradation leading to $\mathrm{SEI}$ layer formation at the $\mathrm{Li}^{0}$ anode. The drop in cell voltage at the higher current densities may be the result of Li dendrites so thin as not to be easily observable by post-mortem analysis, and which leak only a small amount of current. One hypothesis is that the dendrites grow in the grain boundaries of the $(\mathrm{ADN})_{2} \mathrm{LiPF}_{6}$ cocrystals. Support for this hypothesis comes from cycling data (Figure S16) on two half-cells: Cell 1 (Figure S16a), studied at RT, which fails at C/2 rate, and cell 2 (Figure S16b), at $10{ }^{0} \mathrm{C}$, which survives cycling at $1 \mathrm{C}$ rate and recovers. The failure of cell 1 and recovery of cell 2 can be attributed to: at $25{ }^{\circ} \mathrm{C}$, the grain boundary region is more mobile, allowing $\mathrm{Li}^{+}$ion mobility and dendrite growth causing cell failure, while near the freezing point of the "free" or interstitial (half $\mathrm{Li}$ coordinated and half free) $\mathrm{ADN}, \mathrm{Li}^{+}$ions cannot migrate which prevents both charging/discharging, as well as dendrite growth.

Excellent cycling data were obtained in $\mathrm{Li}^{0} /(\mathrm{ADN})_{2} \mathrm{LiPF}_{6} / \mathrm{LiFePO}_{4}$ half-cells at $\mathrm{C} / 20, \mathrm{C} / 10$, and $\mathrm{C} / 5$ rates $\left(\sim 140 \mathrm{mAh}^{-1}\right)$ with little capacity fade (Figure S16) between 2.7 and $4 \mathrm{~V}$. The $\mathrm{C} / 10$ data ran for $>70$ cycles before capacity fade (Figure $\mathbf{4 f}$ ). The impedance data obtained before and after cycling at $10{ }^{\circ} \mathrm{C}$ shows a growth of the interfacial resistance at the Li anode, with little change at the $\mathrm{LiFePO}_{4}$ cathode. Further studies are needed to better understand the failure mechanisms more completely. However, these results are improved compared with the results obtained in related previous studies. For instance, the addition of additives (vinyl carbonate, fluoroethylene carbonate) to liquid $\mathrm{ADN} / 1 \mathrm{M}$ LiTFSI/0.25M $\mathrm{LiBF}_{4}$ electrolytes $^{53}$ was required to increase cycling performance (to 100 cycles at $\mathrm{C} / 5$ ). Using lithium titanate $\left(\mathrm{Li}_{4} \mathrm{Ti}_{5} \mathrm{O}_{12}, \mathrm{LTO}\right)$ anodes (charge plateau at $1.55 \mathrm{~V}$ vs. $\mathrm{Li} / \mathrm{Li}^{+}$) and high voltage cathodes $\mathrm{Li} \mathrm{Ni} \mathrm{Co} \mathrm{Mn} \mathrm{O}_{2}(\mathrm{NMC})$, specific cell capacities of $170 \mathrm{mAh} / \mathrm{g}$ were obtained only at low rates $(\mathrm{C} / 20)$ for 200 cycles $^{44}$. 


\section{Mechanism of ion transport}

The $(\mathrm{ADN})_{2} \mathrm{LiPF}_{6}$ co-crystals are also of interest due to their likely mechanism of conduction. For polymer electrolytes above $\mathrm{T}_{\mathrm{g}}$ the diffusion of the $\mathrm{Li}^{+}$ions is coupled to the slow backbone dynamics of the polymer chain ${ }^{54}$. In organic solvents, there is a vehicular diffusion mechanism of solvated $\mathrm{Li}$ ions ${ }^{55}$. In both cases, the fluidity of the matrices often results in linear diffusion and MD simulations become useful for the calculation of the diffusion coefficient, D. In the cases where polymer electrolytes solidify, a high temperature MD simulation is often used to estimate ion mobility precisely. Inorganic solid electrolytes (e.g., LISICON, garnets) usually possess a strongly bonded, thermally stable sublattice of the anionic component of the electrolyte, and a mobile sublattice of $\mathrm{Li}^{+}$ions. The fixed anionic sublattice in LISICONs enables modeling of $\mathrm{Li}^{+}$ ion diffusion- as MD simulations can be performed at sufficiently high-temperatures without destroying the sublattice matrix leading to good jump statistics even at small timescales.

In contrast to other solid electrolytes, our family of co-crystalline electrolytes does not possess a stable anionic sublattice and/or fluidity at high temperatures, which pose serious limitations on the implementation of simulation methods; e.g. NVT simulations on Model P did not show ionic jumps even at long timescales (Figure S18), nor did an analysis based on calculations of the self-part of van Hove autocorrelation function $(\mathrm{vH} \mathrm{ACF})^{56}$ (Figure S18). To address these challenges, we perform high-temperature molecular simulations along with introduction of ionic defects to model ionic diffusion in the $(\mathrm{ADN})_{2} \mathrm{LiPF}_{6}$ cocrystals. This approach provides improved jump statistics and enables understanding of ionic diffusion from classical simulations. MD simulations on defected supercells (model $D$ ) were employed where four vacancy sites of cations and anions were created, each at random places in the supercell (two defects were at least $1.5 \mathrm{~nm}$ away from each 
other in order to prevent any initial interactions among vacancy sites). Further, we simulated model $D$ for a timescale of $50 \mathrm{~ns}$ at $\mathrm{T}=400 \mathrm{~K}$ and for $20 \mathrm{~ns}$ at $\mathrm{T}=450 \mathrm{~K}$ under $N V T$ ensemble conditions. For the simulations on model $D$, the trajectory was recorded at every $5 \mathrm{ps}$ to obtain trajectory maps. At $\mathrm{T}=400 \mathrm{~K}$ (Figure 5a-5c), the map shows that $\mathrm{Li}^{+}$ions jump to the interstitial sites and occupy the vacancy sites. Between 30 to 40 ns (Figure 5d), a few interstitial jumps for $\mathrm{Li}^{+}$ions were observed in the cocrystals. At $\mathrm{T}=450 \mathrm{~K}$ (Figure 5e-5g), the interstitial jumps are observed more frequently compared to those at $400 \mathrm{~K}$. However at $t>10 \mathrm{~ns}$, the structure collapses at $\mathrm{T}=450 \mathrm{~K}$ suggesting decomposition of the bulk at a lower temperature $\left(\mathrm{T}_{d, \text { sim }}=475 \mathrm{~K}\right.$ from model $\left.P\right)$ due to the presence of vacancy sites. The MSD vs. time plot for model $D$ at $\mathrm{T}=400 \mathrm{~K}$ (Figure S19a), shows that the $\mathrm{Li}^{+}$ions remain trapped and only a few jump events are probable at these timescales. Since $\mathrm{PF}_{6}^{-}$anions are not present in a confined environment as are the $\mathrm{Li}^{+}$ions, the initial oscillations that cause ballistic diffusion are larger in $\mathrm{PF}_{6}{ }^{-}$compared to $\mathrm{Li}^{+}$. At $\mathrm{T}=450 \mathrm{~K}$, as the trajectory maps show a significant number of jump events (Figure 5e-5g), a linear diffusion for $\mathrm{Li}^{+}$and $\mathrm{PF}_{6}{ }^{-}$ions is observed even at very short timescales (Figure S19b). The MSD is calculated for both $\mathrm{Li}^{+}$and $\mathrm{PF}_{6}{ }^{-}$ions for a trajectory of $20 \mathrm{~ns}$, where the $\mathrm{Li}^{+}---\mathrm{N}$ cages break and various sublattices become completely mobile after $10 \mathrm{~ns}$. Thus, the diffusion coefficients for $\mathrm{Li}^{+}$and $\mathrm{PF}_{6}-$ ions were calculated for two time intervals: $0-10 \mathrm{~ns}$ and $10-20 \mathrm{~ns}$. From $0-10 \mathrm{~ns}, D_{L i^{+}}=$ $1.32(4) \times 10^{-6} \mathrm{~cm}^{2} / \mathrm{sec}$ and $D_{P F_{6}^{-}}=1.00(5) \times 10^{-6} \mathrm{~cm}^{2} / \mathrm{sec}$, while from $10-20 \mathrm{~ns}, D_{L i^{+}}=1.21(3) \mathrm{x}$ $10^{-6} \mathrm{~cm}^{2} / \mathrm{sec}$ and $D_{P F_{6}^{-}}=1.02(4) \times 10^{-6} \mathrm{~cm}^{2} / \mathrm{sec}$. For the interval $0-10 \mathrm{~ns}$, the calculated transference number for $\mathrm{Li}^{+}$ions is, $t_{L i^{+}}=0.57$, and for the interval $10-20, t_{L i^{+}}=0.54$, in good agreement with the experimentally determined value of 0.54 . 
(a) $400 \mathrm{~K}, 0-5 \mathrm{~ns}$

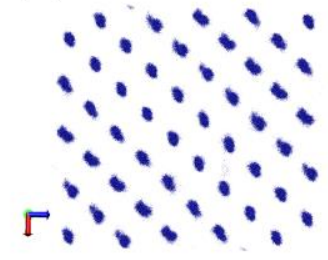

(b) $400 \mathrm{~K}, 5-10 \mathrm{~ns}$

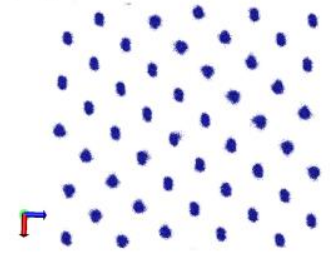

(c)

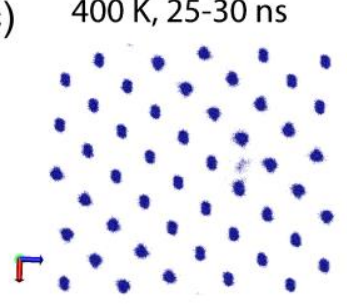

(d)

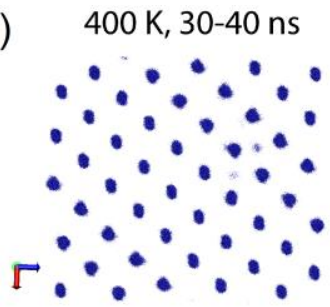

(e) $450 \mathrm{~K}, 0-5 \mathrm{~ns}$

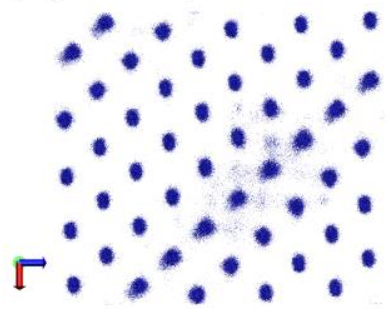

(h)

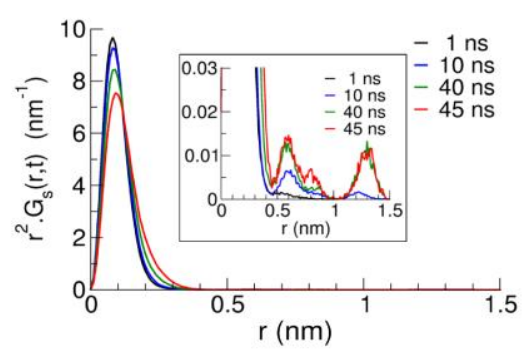

(f) $450 \mathrm{~K}, 5-10 \mathrm{~ns}$

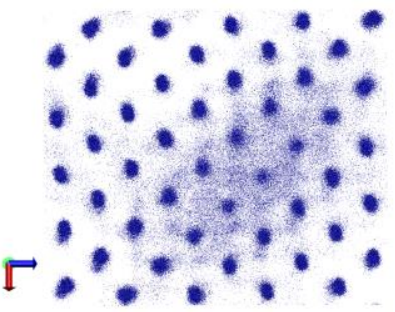

(i)

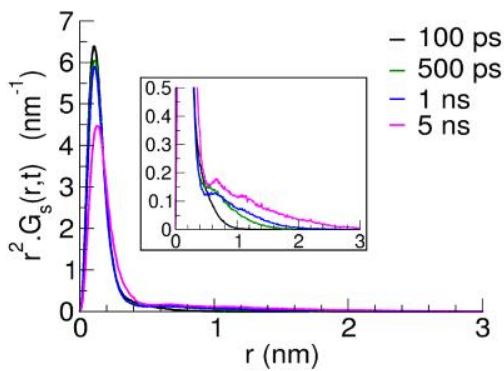

(g) $450 \mathrm{~K}, 10-15 \mathrm{~ns}$

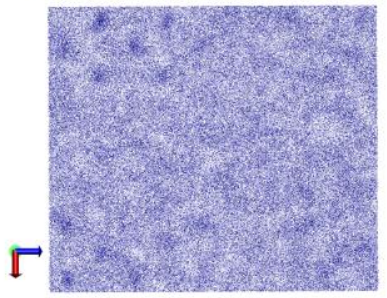

(j)

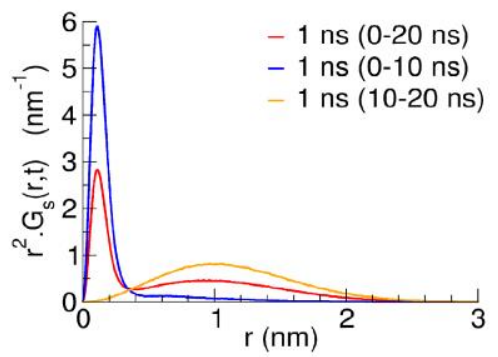

Figure 5. Trajectory map and van-Hove ACF of $\mathbf{L i}^{+}$ions in model $\boldsymbol{D}$ : At $400 \mathrm{~K}$, (a) 0-5 ns, (b) 5-10 ns, (c) 25-30 ns, (d) 30-40 ns; and at $450 \mathrm{~K}$ (e) 0-5 ns, (f) 5-10 ns, (g) 10-15 ns; Self-vH ACF plot for $\mathrm{Li}^{+}$ions at different time intervals in model $D$ at (h) $400 \mathrm{~K}$, from a simulation of $50 \mathrm{~ns}$, (i) $450 \mathrm{~K}$ for simulation time of $0-10 \mathrm{~ns}$ and (j) $450 \mathrm{~K}$ for simulation time of $0-20 \mathrm{~ns}$ and divided into two windows: $0-10 \mathrm{~ns}$ and $10-20 \mathrm{~ns}$.

To quantify the occurrence of jump events in a defected cocrystal at $\mathrm{T}=400 \mathrm{~K}$ and $450 \mathrm{~K}$, self-vH ACF were calculated for model $D$ at these temperatures for different time intervals. At T $=400 \mathrm{~K}$ (Figure $\mathbf{5 h}$ ), the primary peak is observed at $\sim 1 \AA$, corresponding to cage oscillations. At longer time-intervals- $10 \mathrm{~ns}, 40 \mathrm{~ns}$, and $45 \mathrm{~ns}$, very small secondary peaks are observed around $6 \AA$ and $12 \AA$, which can be correlated to $\mathrm{Li}^{+}$ion jumps to the vacancy sites. At $\mathrm{T}=450 \mathrm{~K}$, where the jump frequency is higher, the secondary peaks (jump peaks) span from $5 \AA$ to $30 \AA$, indicating 
a continuity of jump events in the system (Figure 5i). It can also be observed from the inset of Figure 5i that the timescales associated with these jumps decrease rapidly on increasing the temperature from $\mathrm{T}=400 \mathrm{~K}$ to $450 \mathrm{~K}$. Further, Figure 5j shows a comparison of different time windows at $\mathrm{T}=450 \mathrm{~K}$. As mentioned earlier, the crystals melt after $10 \mathrm{~ns}$ at this temperature. The self-vH ACF is calculated from $0-20 \mathrm{~ns}$ and then observed separately in $0-10 \mathrm{~ns}$ and $10-20 \mathrm{~ns}$ time windows with a time interval of $1 \mathrm{~ns}$ to calculate the function. The vH ACF for $0-20 \mathrm{~ns}$ shows probability peaks associated with cage vibrations and jump events. The $0-10$ ns window shows predominantly the cage vibrations while the $10-20$ ns time window shows only the jump events.

Despite the limitations from system characteristics (stronger cationic cage), thermal effects (low $\mathrm{T}_{\mathrm{d}}$ compared to other electrolytes) and computation (classical model and longer timescales), the ionic mobility can be modeled with the observation of jump events and the diffusion associated with them is in good agreement to experiment.

\section{Mechanism of ion conduction from DFT:}

An atomistic mechanism from DFT is presented that quantifies the longevity of interstitial jumps and feasibility of jumps to the vacancy sites. In the unit cell of $(\mathrm{ADN})_{2} \mathrm{LiPF}_{6}$, the shortest possible distance between successive $\mathrm{Li}^{+}$ions is $6.6 \AA$ (6.3 $\AA$ from XRD) which is parallel to the $b$ crystallographic direction (Table S2, Figure S20). To examine all the possible $\mathrm{Li}^{+}$migration channels, several different supercells were created. For these supercells, one $\mathrm{Li}^{+}$ion vacancy site was created to calculate the minimum energy path (MEP) of $\mathrm{Li}^{+}$ion migration between adjacent occupancy sites. The defected supercell images (images: where the defect is located at a different site in the same supercell) were optimized in a fixed volume cell. Various pairs of reactant and 
product were used to examine the MEP for $\mathrm{Li}^{+}$ion migration using NEB calculations. The extrapolation of $\mathrm{Li}^{+}$ion migration paths and calculated activation energy barriers suggested the channel in the $b$-crystallographic direction $\left(\mathrm{Li}^{+}-\mathrm{Li}^{+}=6.5 \AA\right)$ to be the one with the lowest energy (Figure 6). Hence, further results are discussed for this particular case only, while the information about the other paths is provided in the Supporting Information.

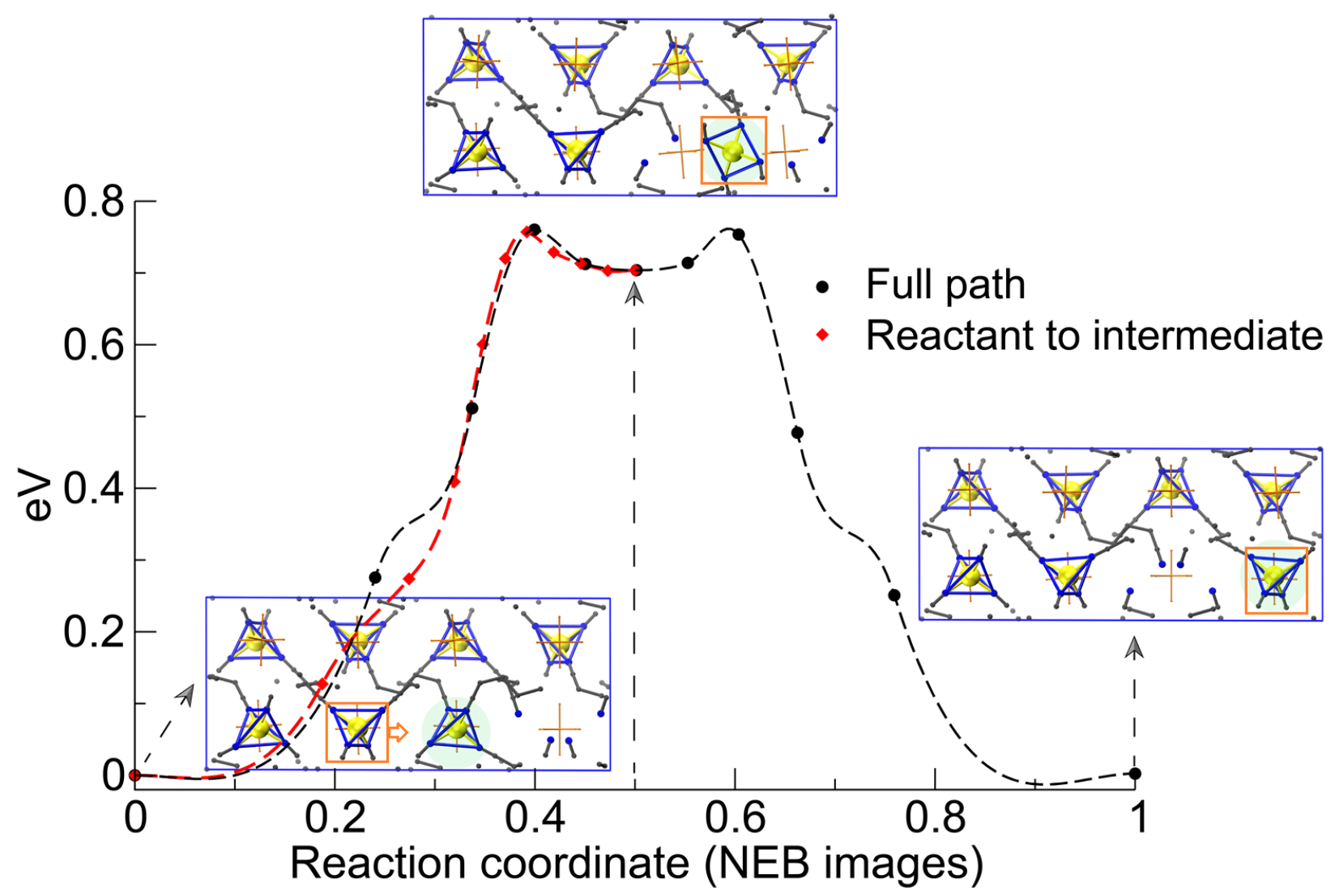

Figure 6. Minimum energy path (MEP) for $\mathrm{Li}^{+}$ion migration in the $b$ - crystallographic direction, as observed from a 1x2x1 supercell of $(\mathbf{A D N})_{2} \mathbf{L i P F}_{6}$ : The geometries of initial, final and intermediate structures are shown above. The location for migrating $\mathrm{Li}^{+}$ion can be seen in the highlighted spot. A dynamic visualization of the $\mathrm{Li}^{+}$ion migration is presented in Supplementary movie 2.

The $\mathrm{Li}^{+}$ions form a sterically unblocked array parallel to the $b$-crystallographic direction with a short distance between the $\mathrm{Li}^{+}$ions, and with no interstitial $\mathrm{PF}_{6}$ anions, in contrast to the paths in the $a$-and $c$-directions. This results in the possibility of a low barrier migration path for 
the $\mathrm{Li}^{+}$ions in this direction. The calculated path of the $\mathrm{Li}^{+}$ion in the $b$-direction shows migration of $\mathrm{Li}^{+}$ions from one occupancy site to a vacancy site via an intermediate (Figure 6, Supplementary movie 2). When a $\mathrm{Li}^{+}$ion defect is introduced in the supercell, the nitrogen atoms of ADN molecules repel one another and vacate the Li site to stabilize the vacancy. While the regular $\mathrm{N} \cdots \mathrm{N}$ distance in $\mathrm{Li}^{+}---\mathrm{N}$ networks is 3.2 to $3.4 \AA$, the presence of a vacancy site increases this distance from $3.6 \AA$ to $5.4 \AA$. A set of 11 intermediate images was used to extrapolate the path of the $\mathrm{Li}^{+}$ion. The climbing image-NEB calculations suggest that a $\mathrm{Li}^{+}$ion migrates via the formation of an intermediate structure just between the two $\mathrm{Li}^{+}$occupancy sites along the $b$ crystallographic direction. The MEP was calculated for initial and intermediate images separately (11 images). The geometry of the intermediate structure (Figure 6) is a $\mathrm{Li}^{+}---\mathrm{N}$ tetrahedron, which forms with a reorientation of two of the four ADN molecules from each end. When the intermediate forms, the remaining two ADN molecules appear to be a part of an elongated tetrahedron. The intermediate structure (relative energy $=0.70 \mathrm{eV}=67 \mathrm{~kJ} / \mathrm{mol}$ ) has two transition state structures at either side of the reaction coordinate with a barrier of $0.75 \mathrm{eV}(=72 \mathrm{~kJ} / \mathrm{mol})$. This activation energy is on the same order as the experimentally determined value (See Figure 4a), though approximately two times larger. The presence of the intermediate structure suggests that the solvent $(\mathrm{ADN})$ coordinated structure is stable and, hence interstitial dislocations along with Schottky defects play a major role in ion transport. The occurrence of an intermediate structure also predicts that there is no involvement of anions during the cation transport, contrary to what has been observed in a similar class of sodium ion electrolyte $(\mathrm{ADN})_{3} \mathrm{NaClO}_{4}$, where both anion and solvent coordinate with the cation leading to the formation of a transition state ${ }^{14}$. 


\section{CONCLUSIONS}

While much research has been expended to optimize crystal structures and doping strategies in inorganic solid electrolytes, there has been much less work on soft-solid crystals. There are significant differences in the structures and mechanisms of ion conduction between these two classes of electrolytes. In contrast to inorganic conductors, the soft-solid crystals of (ADN) ${ }_{2} \mathrm{LiPF}_{6}$ have a solvent mediated migration of $\mathrm{Li}^{+}$ions. The weak interactions between the "hard" $\mathrm{Li}^{+}$ions and "soft" $-\mathrm{C} \equiv \mathrm{N}$ groups, and the fewer contacts (four for $-\mathrm{C} \equiv \mathrm{N}$ vs five for $-\mathrm{O}$ - in glymes ${ }^{6}$ ) are responsible for the three order of magnitude increase in conductivity compared with the crystalline solvate $(\mathrm{EO})_{6} \mathrm{LiPF}_{6}\left(\sigma \sim 10^{-7} \mathrm{~S} / \mathrm{cm}\right)$ prepared using low molar mass polyethylene oxide ${ }^{5,10}$. Further, in the case of inorganic lithium electrolytes, the grain boundary resistance is believed to be greater than the bulk conductivity, while in the case of soft-solid crystals the grain boundaries are composed of fluid organic solvent and thus have better conductivity than the bulk grains.

Similar to the recent developments in ceramic electrolytes, improvements in conductivity for soft co-crystals are expected if 2D or 3D channel systems with a shorter distance between Li sites are synthesized. Another future modification would be to engineer a cocrystal with an optimal solvent and anion that increases the number of vacancy or interstitial sites (e.g., by isovalent or aliovalent doping, or introduction of defects by chain ends (here by introducing a different dinitrile or a mononitrile) as in the case of glyme/LiX complexes $^{9}$ ). Future efforts will explore the incorporation of these deliberate defecting strategies to improve conductivity in these electrolytes. 


\section{METHODS}

\section{General}

Lithium metal, $\mathrm{LiPF}_{6}$ salt, $\mathrm{ADN}$, and diethyl ether $\left(\mathrm{Et}_{2} \mathrm{O}\right)$ were purchased from Sigma-Aldrich. $\mathrm{Et}_{2} \mathrm{O}$ was distilled using sodium benzophenone ketyl as a water/oxygen scavenger. Single-crystal and powder X-ray diffraction data were obtained on a Bruker KAPPA Apex II DUO with sealedtube Mo $\mathrm{K} \alpha$ and $\mathrm{Cu} \mathrm{K} \alpha$ sources, a TRIUMPH monochromator for the molybdenum tube, and an Oxford Cryostream low temperature device. Thermal degradation analysis of $(\mathrm{ADN})_{2} \mathrm{LiPF}_{6}$ crystals was carried out on a Thermogravimetric Analysis (TGA) TA Instruments Hi-Res TGA 2950 at a ramp rate of $10{ }^{\circ} \mathrm{C} \mathrm{min}^{-1}$ with a flow of ultra-pure $\mathrm{N}_{2}$ gas. A Differential Scanning Calorimeter (DSC) TA Instruments 2920 was used to analyze the melt and crystallization temperatures of the $(\mathrm{ADN})_{2} \mathrm{LiPF}_{6}$, with the sample in hermetically sealed Tzero aluminum pans. Samples were scanned from $-120{ }^{\circ} \mathrm{C}$ to $200{ }^{\circ} \mathrm{C}$ at a scan rate of $10{ }^{\circ} \mathrm{C} \cdot \mathrm{min}^{-1}$, under ultra-pure $\mathrm{N}_{2}$ purge. The second cycle of the adiponitrile matrix and $(\mathrm{ADN})_{2} \mathrm{LiPF}_{6}$ powder was reported out of the two measured cycles. Scanning electron microscope (SEM) data were acquired on a FEI Quanta 450FEG SEM) with energy-dispersive X-ray spectroscopy (EDS) capability (Oxford Aztec Energy Advanced EDS System). Raman spectra were recorded in the $100-3000 \mathrm{~cm}^{-1}$ region at room temperature using a Horiba LabRAM HR Evolution Raman spectrometer, with a resolution of $1.8 \mathrm{~cm}^{-1}$, an excitation wavelength of $532 \mathrm{~nm}, 60 \mathrm{~mW}$ power, and a grating groove density of $600 \mathrm{gr} / \mathrm{mm}$. Samples were measured with 8 acquisitions, and 2 to 8 seconds each, depending on peak intensity.

For the conductivity measurements, polycrystalline $(\mathrm{ADN})_{2} \mathrm{LiPF}_{6}$ powder incorporated in the glass fiber separator or prepared by pressing at 800 psi in a hydraulic crimper in an argon purged glove 
box, was used. The conductivity measurements were performed in a homemade electrochemical cell placed in a $\mathrm{N}_{2}$ purged, temperature-controlled gas chromatography (GC) oven. Temperaturedependent bulk impedance data was measured by AC electrochemical impedance spectroscopy (EIS) using a Gamry Interface 1000 potentiostat/galvanostat/ZRA in the frequency range $0.1-1 \mathrm{MHz}$ in a temperature range between $80{ }^{\circ} \mathrm{C}$ and $-10{ }^{\circ} \mathrm{C}$ with increments of $10{ }^{\circ} \mathrm{C}$. The cell was thermally equilibrated for 30 minutes at each temperature before the bulk impedance was measured during both the cooling and heating cycles.

\section{Synthesis:}

$\mathrm{LiPF}_{6}(151 \mathrm{mg}, 1.0 \mathrm{mmols})$ was dissolved in excess adiponitrile (ADN) $(4.5 \mathrm{ml}, 4.0 \mathrm{mmol})$ by heating the mixture to $165{ }^{\circ} \mathrm{C}$ under an argon atmosphere until it dissolved. The $\mathrm{LiPF}_{6}$ was not soluble in ADP at RT. Upon cooling, crystalline material started to form at about $115^{\circ} \mathrm{C}$ and was complete at room temperature (RT). A single crystal was removed from the precipitate for X-ray structure determination, and the remaining solid was rinsed five times with excess $\mathrm{Et}_{2} \mathrm{O}$ and dried under vacuum for $\sim 20$ minutes to remove the residual amount of $\mathrm{ADN}$ and $\mathrm{Et}_{2} \mathrm{O}$, after which the co-crystal appeared dry. The sample was incorporated concomitantly during the synthesis into Whatman glass microfiber filters (GF), grade GF/A (Sigma-Aldrich) $0.26 \mathrm{~mm}$ thickness. The cocrystal in the glass fiber filter was used as the separator between the electrodes to control the size and the amount of the electrolyte in the electrochemical experiments.

For all other electrochemical measurements $\left(\mathrm{Li}^{+}\right.$ion transference numbers, plating and stripping, cyclic voltammetry, linear sweep voltammetry, and full cell cycling) the $(\mathrm{ADN})_{2} \mathrm{LiPF}_{6}$ was incorporated in the glass filters (during the synthesis). Before use, the lithium metal was polished using Teflon blocks. For the plating and striping experiments at room temperature with the 
$\mathrm{Li}^{0} /(\mathrm{ADN})_{2} \mathrm{LiPF}_{6} / \mathrm{Li}^{0}$ cell, current densities of $0.01 \mathrm{~mA} / \mathrm{cm}^{2}$ for 1 to 120 cycles, $0.05 \mathrm{~mA} / \mathrm{cm}^{2}$ for 121 to 180 cycles, and $0.1 \mathrm{~mA} / \mathrm{cm}^{2}$ for 181 to 240 cycles were used. $\mathrm{Li}^{+}$ion transference numbers were obtained by the method of combined ac and dc measurements ${ }^{57,58}$. The cathode was prepared from $\mathrm{LiFePO}_{4} /$ carbon black/PVDF binder (8/1/1 by weight) using N-methyl-2-pyrrolidone (NMP) to form a slurry that was doctor-bladed onto battery-grade aluminum foil to form $1.9-2.2 \mathrm{mg} / \mathrm{cm}^{2}$ electrodes. The electrodes were dried in a vacuum oven overnight at $120^{\circ} \mathrm{C}$. The dried electrodes were calendared with a Durston flat agile F130 mm rolling mill mechanical presser.

\section{MD simulations:}

Force field parameters for bonded and Lennard Jones (vdW) interactions for ADN were taken from the OPLS all-atom force field ${ }^{59}$. The partial charges on all atoms of ADN were calculated from the MP2//aug-cc-PVDZ optimized structure using the CHELPG method ${ }^{60}$. Since the $\mathrm{Li}^{+}$ion is present in tetra coordination with $\mathrm{ADN}$, the partial charge on $\mathrm{Li}^{+}$was calculated using the optimized structure in Figure S21 with a long range and dispersion corrected $\omega$ B97xD functional with $6-311++\mathrm{G}(\mathrm{d}, \mathrm{p})_{\text {optimization }} /$ aug-cc-PVDZ charge calculation basis set. This calculation suggested a partial charge of 0.845 e unit on the $\mathrm{Li}^{+}$ions. The charge value on the $\mathrm{Li}^{+}$ion $(0.845 \mathrm{e})$ was used as the scaling factor to rescale the partial charges on $\mathrm{PF}_{6}$ ions (obtained from MP2//aug-cc-PVDZ calculations, separately). To compute theoretical Raman spectra for $\mathrm{ADN}$ and $(\mathrm{ADN})_{2} \mathrm{LiPF}_{6}$, vibrational frequencies were calculated using $\mathrm{PBE} / 6-311++\mathrm{G}(\mathrm{d}, \mathrm{p})$ for the structures optimized using the same functional/basis set. All the gas phase quantum chemistry calculations were carried out using the GAUSSIAN 9.0 software package ${ }^{61}$. Detailed protocol for force-field development is provided in the Supporting Information. 
A supercell of $5 \times 5 \times 5$ unit cells $(20,000$ atoms $)$ of $(\mathrm{ADN})_{2} \mathrm{LiPF}_{6}$ was constructed in a cuboid with the dimensions of $55.35 \times 64.75 \times 63.25 \AA^{3}$. This model was used for simulations under periodic boundary conditions to represent the bulk phase, and hence, is designated as model $P$. However, since the surface atoms have a large contribution towards the conduction and decomposition of these co-crystalline electrolytes, a different model $V$ was used to understand the structure, dynamics and thermal behavior at the surface. Model $V$ was constructed by placing a $5 \times 5 \times 5$ supercell in a cube of $200 \AA$ Aside. GROMACS 5.0 .7 software $^{62}$ was used for simulations and analysis along with VMD 1.9.3 software ${ }^{63}$ for visualization of trajectories. The supercell models were energy minimized using standard protocols and algorithms implemented in the code. All the simulations for model $P$ were carried out using $N p T$ ensemble conditions, while for model $V$, canonical ensemble conditions were used. Details of temperature and pressure couplings and other MD parameters can be found in another work on a similar co-crystalline electrolyte material ${ }^{47}$.

\section{Plane-wave periodic DFT calculations:}

To examine the mechanism of conduction at the atomic level with precise energetics, PW-DFT calculations were performed using the QUANTUM ESPRESSO 6.1 software package ${ }^{64}$. A projector-augmented-wave-basis set (Kresse-Joubert) ${ }^{65}$ was used with PBE pseudopotentials ${ }^{66}$ with a cut-off of $60 \mathrm{Ry}$ and 360 Ry for kinetic energy and electron density, respectively. A unit cell of $(\mathrm{ADN})_{2} \mathrm{LiPF}_{6}$ cocrystals (from single-crystal $\mathrm{XRD}$ data) was relaxed in a fixed volume box and later in a variable cell manner to energy minimize the crystal structure. A threshold of $10^{-7} \mathrm{Ry}$ was used for electronic optimization and $10^{-3} \mathrm{Ry} / \mathrm{Bohr}$ for force minimization. Table $\mathbf{S 2}$ shows a comparison of unit cell parameters obtained from single-crystal XRD data and variable cell relaxation DFT calculations. To investigate the path of $\mathrm{Li}^{+}$ion conduction in the cocrystal, $1 \times 1 \times 2$, $3 \times 1 \times 1$ and $2 \times 1 \times 2$ supercells were created and optimized using the above discussed protocols. Due 
to the large system size of these supercells, all the calculations were performed with a $\Gamma$-only 1x1x1 k-mesh. For every supercell, a pair of $\mathrm{Li}^{+}$ion-defected configurations was used as an initial and final image for Nudged Elastic Band (NEB) calculations to interpolate the minimum energy path (MEP). Several sets of images were used to obtain the MEP, with a threshold of $0.1 \mathrm{eV} / \mathrm{Bohr}$ used for every individual image. Further, the MEP was refined using the climbing image $(\mathrm{CI})$ NEB method ${ }^{67}$ with a more precise threshold of $0.01 \mathrm{eV} / \mathrm{Bohr}$ for every image along the path.

\section{ASSOCIATED CONTENT}

\section{Supporting Information.}

Powder X-ray diffraction, data, TGA, SEM, DC polarization and cycling data, additional details of simulation and DFT, and crystallographic tables. Crystallographic data is also available from the CCDC under deposition number 1986269.

\section{Acknowledgements}

Support of this work by the National Science Foundation under award 1437814, by DST Nanomission SR/NM/TP-13/2016 and by IUSSTF/JC-031/2017 is gratefully acknowledged. We acknowledge IISER Pune, Temple's EFRC cluster which is supported by the Center for Complex Materials, an Energy Frontier Research Center funded by the U.S. Department of Energy, Office of Science, Basic Energy Sciences, under Award\#DESC0012575, and Temple University's HPC clusters, which were supported in part by the National Science Foundation through major research instrumentation grant number 1625061 and by the US Army Research Laboratory under contract number W911NF-16-2-018 for computational resources. P. P. acknowledges foreign Fulbright Program from USDOS for a visiting research fellowship. For SEM work, we acknowledge the CoE-NIC facility at Temple University founded on DoD DURIP Award N0014-12-1-0777 from the Office of Naval Research. 


\section{Author contributions}

Birane Fall ${ }^{a}$, Prabhat Prakash ${ }^{b}$, Jordan Aguirre ${ }^{a}$, Sumanth Chereddy ${ }^{a}$, Parameswara Rao Chinnam $^{a}$, Dmitriy Dikin ${ }^{c}$, Arun Venkatnathan ${ }^{b *}$, Stephanie L. Wunder ${ }^{a *}$, Michael J. Zdilla ${ }^{a *}$

B. F. discovered and optimized the synthesis of the electrolyte, obtained electrochemical and physical data and assisted in interpretation, constructed and tested electrochemical cells. P. P. led computational efforts on MD simulations and DFT calculations, assisted with optimization of synthetic protocol and assisted with electrochemical data collection and interpretation. J. A. collected and interpreted Raman data. S. C. prepared cathode composite, assisted with cell assembly and with electrochemical data interpretation. P. R. C. designed electrochemical experimental testing, devised experimental strategy, and assisted with data interpretation. D. D. Obtained SEM, EDS data and assisted with interpretation. A. V. supervised computational efforts. S. L. W. supervised electrochemistry and characterization efforts. M. J. Z. supervised synthetic and X-ray characterization efforts.

\section{Competing interests}

The authors declare no competing interests.

\section{REFERENCES:}

1. Fergus, J. W. Ceramic and polymeric solid electrolytes for lithium-ion batteries. J. Power Sources 195, 4554-4569 (2010).

2. Gao, Z. et al. Promises, Challenges, and Recent Progress of Inorganic Solid-State Electrolytes for All-Solid-State Lithium Batteries. Adv. Mater. 30, 1-27 (2018).

3. Palacín, M. R. Recent advances in rechargeable battery materials: a chemist's perspective. 
Chem. Soc. Rev. 38, 2565 (2009).

4. Lau, J. et al. Sulfide Solid Electrolytes for Lithium Battery Applications. Adv. Energy Mater. 8, 1-24 (2018).

5. Gadjourova, Z., Marero, D. M., Andersen, K. H., Andreev, Y. G. \& Bruce, P. G. Structures of the polymer electrolyte complexes PEO6 : LiXF6 $(\mathrm{X}=\mathrm{P}, \mathrm{Sb})$, determined from neutron powder diffraction data. Chem. Mater. 13, 1282-1285 (2001).

6. MacGlashan, G. S., Andreev, Y. G. \& Bruce, P. G. Structure of the polymer electrolyte poly(ethylene oxide)(6): LiAsF6. Nature 398, 792-794 (1999).

7. Gadjourova, Z., Andreev, Y. G., Tunstall, D. P. \& Bruce, P. G. Ionic conductivity in crystalline polymer electrolytes. Nature 412, 520-523 (2001).

8. Zhang, C. H., Ainsworth, D., Andreev, Y. G. \& Bruce, P. G. Ionic conductivity in the solid glyme complexes [CH3O(CH2CH2O)(n)CH3]: LiAsF6 (n=3,4). J. Am. Chem. Soc. 129, 8700-8701 (2007).

9. Staunton, E., Andreev, Y. G. \& Bruce, P. G. Factors influencing the conductivity of crystalline polymer electrolytes. Faraday Discuss. 134, 143-156 (2007).

10. Stoeva, Z., Martin-Litas, I., Staunton, E., Andreev, Y. G. \& Bruce, P. G. Ionic conductivity in the crystalline polymer electrolytes PEO6: LiXF6, X = P, As, Sb. J. Am. Chem. Soc. 125, 4619-4626 (2003).

11. Chinnam, P. R., Clymer, R. N., Jalil, A. A., Wunder, S. L. \& Zdilla, M. J. Bulk-Phase Ion Conduction in Cocrystalline LiCl- $N, N$-Dimethylformamide: A New Paradigm for Solid Electrolytes Based upon the Pearson Hard-Soft Acid-Base Concept. Chem. Mater. 27, 5479-5482 (2015). 
12. Chinnam, P. R. et al. A Self-Binding, Melt-Castable, Crystalline Organic Electrolyte for Sodium Ion Conduction. Angew. Chemie Int. Ed. 55, 15254-15257 (2016).

13. Fall, B. et al. Crystal structure and ionic conductivity of the soft solid crystal: isoquinoline ${ }_{3}(\mathrm{LiCl})_{2}$. Ionics (Kiel). 24, 343-349 (2018).

14. Fall, B. et al. Experimental and theoretical investigation of the ion conduction mechanism of tris(adiponitrile)perchloratosodium, a self-binding, melt-castable crystalline sodium electrolyte. Chem. Mater. 31, 8850-8863 (2019).

15. Abouimrane, A., Ding, J. \& Davidson, I. J. Liquid electrolyte based on lithium bisfluorosulfonyl imide salt: Aluminum corrosion studies and lithium ion battery investigations. J. Power Sources 189, 693-696 (2009).

16. Abouimrane, A., Whitfield, P. S., Niketic, S. \& Davidson, I. J. Investigation of Li salt doped succinonitrile as potential solid electrolytes for lithium batteries. J. Power Sources 174, 883-888 (2007).

17. Alarco, P.-J., Abu-Lebdeh, Y., Abouimrane, A. \& Armand, M. The plastic-crystalline phase of succinonitrile as a universal matrix for solid-state ionic conductors. Nat. Mater. 3, 476481 (2004).

18. Choe, H. S., Carroll, B. G., Pasquariello, D. M. \& Abraham, K. M. Characterization of Some Polyacrylonitrile-Based Electrolytes. Chem. Mater. 9, 369-379 (1997).

19. Carol, P., Ramakrishnan, P., John, B. \& Cheruvally, G. Preparation and characterization of electrospun poly(acrylonitrile) fibrous membrane based gel polymer electrolytes for lithium-ion batteries. J. Power Sources 196, 10156-10162 (2011).

20. Zhou, D. et al. In Situ Synthesis of a Hierarchical All-Solid-State Electrolyte Based on 
Nitrile Materials for High-Performance Lithium-Ion Batteries. Adv. Energy Mater. 5, 1500353 (2015).

21. Abraham, K. M. Li+-Conductive Solid Polymer Electrolytes with Liquid-Like Conductivity. J. Electrochem. Soc. 137, 1657 (1990).

22. Watanabe, M., Kanba, M., Nagaoka, K. \& Shinohara, I. Ionic conductivity of hybrid films composed of polyacrylonitrile, ethylene carbonate, and LiClO4. J. Polym. Sci. Polym. Phys. Ed. 21, 939-948 (1983).

23. Croce, F., Brown, S. D., Greenbaum, S. G., Slane, S. M. \& Salomon, M. Lithium-7 NMR and ionic conductivity studies of gel electrolytes based on polyacrylonitrile. Chem. Mater. 5, 1268-1272 (1993).

24. Watanabe, M., Kanba, M., Nagaoka, K. \& Shinohara, I. Ionic conductivity of hybrid films based on polyacrylonitrile and their battery application. J. Appl. Polym. Sci. 27, 4191-4198 (1982).

25. Hong, H., Liquan, C., Xuejie, H. \& Rongjian, X. Studies on PAN-based lithium salt complex. Electrochim. Acta 37, 1671-1673 (1992).

26. Peramunage, D. Polyacrylonitrile-Based Electrolytes with Ternary Solvent Mixtures as Plasticizers. J. Electrochem. Soc. 142, 1789 (1995).

27. Huang, B. Lithium ion conduction in polymer electrolytes based on PAN. Solid State Ionics 85, 79-84 (1996).

28. Forsyth, M., Sun, J. \& Macfarlane, D. R. Novel polymer-in-salt electrolytes based on polyacrylonitrile (PAN)-lithium triflate salt mixtures. Solid State Ionics 112, 161-163 (1998). 
29. Yoon, H.-K., Chung, W.-S. \& Jo, N.-J. Study on ionic transport mechanism and interactions between salt and polymer chain in PAN based solid polymer electrolytes containing LiCF3SO3. Electrochim. Acta 50, 289-293 (2004).

30. Ferry, A., Edman, L., Forsyth, M., MacFarlane, D. R. \& Sun, J. Connectivity, ionic interactions, and migration in a fast-ion-conducting polymer-in-salt electrolyte based on poly(acrylonitrile) and LiCF3SO3. J. Appl. Phys. 86, 2346-2348 (1999).

31. Forsyth, M., Sun, J., Macfarlane, D. R. \& Hill, A. J. Compositional dependence of free volume in PAN/LiCF3SO3 polymer-in-salt electrolytes and the effect on ionic conductivity. J. Polym. Sci. Part B Polym. Phys. 38, 341-350 (2000).

32. Hu, P. et al. Progress in nitrile-based polymer electrolytes for high performance lithium batteries. J. Mater. Chem. A 4, 10070-10083 (2016).

33. Abu-Lebdeh, Y. \& Davidson, I. New electrolytes based on glutaronitrile for high energy/power Li-ion batteries. J. Power Sources 189, 576-579 (2009).

34. $\mathrm{Xu}, \mathrm{K}$. Electrolytes and Interphases in Li-Ion Batteries and Beyond. Chem. Rev. 114, 11503-11618 (2014).

35. Li, W., Song, B. \& Manthiram, A. High-voltage positive electrode materials for lithium-ion batteries. Chem. Soc. Rev. 46, 3006-3059 (2017).

36. Nanini-Maury, E. et al. Electrochemical behavior of sebaconitrile as a cosolvent in the formulation of electrolytes at high potentials for lithium-ion batteries. Electrochim. Acta 115, 223-233 (2014).

37. Tan, S., Ji, Y. J., Zhang, Z. R. \& Yang, Y. Recent Progress in Research on High-Voltage Electrolytes for Lithium-Ion Batteries. ChemPhysChem 15, 1956-1969 (2014). 
38. Wang, X. et al. Adiponitrile as Lithium-Ion Battery Electrolyte Additive: A Positive and Peculiar Effect on High-Voltage Systems. ACS Appl. Energy Mater. 1, 5347-5354 (2018).

39. Lee, S. H., Hwang, J. Y., Park, S. J., Park, G. T. \& Sun, Y. K. Adiponitrile (C6H8N2): A New Bi-Functional Additive for High-Performance Li-Metal Batteries. Adv. Funct. Mater. 29, 9 (2019).

40. Di Censo, D., Exnar, I. \& Graetzel, M. Non-corrosive electrolyte compositions containing perfluoroalkylsulfonyl imides for high power Li-ion batteries. Electrochem. commun. 7, 1000-1006 (2005).

41. Abu-Lebdeh, Y. \& Davidson, I. High-Voltage Electrolytes Based on Adiponitrile for LiIon Batteries. J. Electrochem. Soc. 156, A60 (2009).

42. Yamada, Y. et al. Unusual Stability of Acetonitrile-Based Superconcentrated Electrolytes for Fast-Charging Lithium-Ion Batteries. J. Am. Chem. Soc. 136, 5039-5046 (2014).

43. Ugata, Y. et al. Li-ion hopping conduction in highly concentrated lithium bis(fluorosulfonyl)amide/dinitrile liquid electrolytes. Phys. Chem. Chem. Phys. 21, 97599768 (2019).

44. Farhat, D., Ghamouss, F., Maibach, J., Edström, K. \& Lemordant, D. Adiponitrile-Lithium Bis(trimethylsulfonyl)imide Solutions as Alkyl Carbonate-free Electrolytes for Li 4 Ti 5 O 12 (LTO)/LiNi 1/3 Co 1/3 Mn 1/3 O 2 (NMC) Li-Ion Batteries. ChemPhysChem 18, 13331344 (2017).

45. Oldiges, K., von Aspern, N., Cekic-Laskovic, I., Winter, M. \& Brunklaus, G. Impact of Trifluoromethylation of Adiponitrile on Aluminum Dissolution Behavior in Dinitrile-Based Electrolytes. J. Electrochem. Soc. 165, A3773-A3781 (2018). 
46. Persson, K. Materials Data on LiPF6 (SG:148) by Materials Project. doi:10.17188/1313000.

47. Prakash, P. et al. Unravelling the structural and dynamical complexity of the equilibrium liquid grain-binding layer in highly conductive organic crystalline electrolytes. J. Mater. Chem. A 6, 4394-4404 (2018).

48. Ue, M., Takeda, M., Takehara, M. \& Mori, S. Electrochemical properties of quaternary ammonium salts for electrochemical capacitors. J. Electrochem. Soc. 144, 2684-2688 (1997).

49. Cheng, X.-B. \& Zhang, Q. Dendrite-free lithium metal anodes: stable solid electrolyte interphases for high-efficiency batteries. J. Mater. Chem. A 3, 7207-7209 (2015).

50. Ue, M., Ida, K. \& Mori, S. Electrochemical properties of organic liquid electrolytes based on quarternary onium salts for electrical double-layer capacitors. J. Electrochem. Soc. 141, 2989-2996 (1994).

51. Goodenough, J. B. \& Kim, Y. Challenges for Rechargeable Li Batteries †. Chem. Mater. 22, 587-603 (2010).

52. Yamada, Y. \& Yamada, A. Superconcentrated Electrolytes to Create New Interfacial Chemistry in Non-aqueous and Aqueous Rechargeable Batteries. Chem. Lett. 46, 10561064 (2017).

53. Gmitter, A. J., Plitz, I. \& Amatucci, G. G. High Concentration Dinitrile, 3Alkoxypropionitrile, and Linear Carbonate Electrolytes Enabled by Vinylene and Monofluoroethylene Carbonate Additives. J. Electrochem. Soc. 159, A370-A379 (2012).

54. Long, L. Z., Wang, S. J., Xiao, M. \& Meng, Y. Z. Polymer electrolytes for lithium polymer batteries. J. Mater. Chem. A 4, 10038-10069 (2016). 
55. $\mathrm{Xu}, \mathrm{K}$. Nonaqueous liquid electrolytes for lithium-based rechargeable batteries. Chem. Rev. 104, 4303-4417 (2004).

56. Van Hove, L. Correlations in space and time and born approximation scattering in systems of interacting particles. Phys. Rev. 95, 249-262 (1954).

57. Bruce, P. G. \& Vincent, C. A. Steady state current flow in solid binary electrolyte cells. J. Electroanal. Chem. 225, 1-17 (1987).

58. Evans, J., Vincent, C. A. \& Bruce, P. G. Electrochemical measurement of transference numbers in polymer electrolytes. Polymer (Guildf). 28, 2324-2328 (1987).

59. Jorgensen, W. L., Maxwell, D. S. \& Tirado-Rives, J. Development and testing of the OPLS all-atom force field on conformational energetics and properties of organic liquids. J. Am. Chem. Soc. 118, 11225-11236 (1996).

60. Breneman, C. M. \& Wiberg, K. B. Determining atom centered monopoles from molecular electrostatic potentials. The need for high sampling density in formamide conformational analysis. J. Comput. Chem. 11, 361-373 (1990).

61. Frisch, M. J. et al. Gaussian 09, Revision D.01. (2010).

62. Abraham, M. J. et al. Gromacs: High performance molecular simulations through multilevel parallelism from laptops to supercomputers. SoftwareX 1-2, 19-25 (2015).

63. Humphrey, W., Dalke, A. \& Schulten, K. VMD: Visual molecular dynamics. J. Mol. Graph. 14, 33-38 (1996).

64. Giannozzi, P. et al. Advanced capabilities for materials modelling with Quantum ESPRESSO. J. Phys. Condens. Matter 29, 465901 (2017).

65. Kresse, G. \& Joubert, D. From ultrasoft pseudopotentials to the projector augmented-wave 
method. Phys. Rev. B 59, 1758-1775 (1999).

66. Perdew, J. P., Ernzerhof, M. \& Burke, K. Rationale for mixing exact exchange with density functional approximations. J. Chem. Phys. 105, 9982-9985 (1996).

67. Henkelman, G., Uberuaga, B. P. \& Jónsson, H. A climbing image nudged elastic band method for finding saddle points and minimum energy paths. J. Chem. Phys. 113, 99019904 (2000). 